\title{
Myocardial Perfusion Image in Asymptomatic Postmenopausal Women with Physical Inactivity and Overweight
}

\author{
Chen-Lin Chien $^{\mathrm{a}}$ Yen-Wen Wu ${ }^{\mathrm{b}, \mathrm{c}}$ Wei-Shiung Yang ${ }^{\mathrm{d}, \mathrm{e}}$ Pan-Chyr Yang ${ }^{\mathrm{e}, \mathrm{f}}$ Hui-Min Su ${ }^{\mathrm{g}}$ \\ Ying-Tai Wu ${ }^{\mathrm{a}}$ \\ a School and Graduate Institute of Physical Therapy, College of Medicine, National Taiwan University, \\ ${ }^{\mathrm{b}}$ Division of Cardiology, Department of Internal Medicine, \\ ${ }^{\mathrm{C}}$ Department of Nuclear Medicine, \\ ${ }^{\mathrm{d}}$ Division of Endocrinology and Metabolism, Department of Internal Medicine, National Taiwan University Hospital, \\ and College of Medicine, National Taiwan University, Taipei, Taiwan; \\ ${ }^{\text {e } G r a d u a t e ~ I n s t i t u t e ~ o f ~ C l i n i c a l ~ M e d i c i n e, ~ a n d ~ D e p a r t m e n t ~ o f ~ M e d i c i n e, ~ C o l l e g e ~ o f ~ M e d i c i n e, ~ N a t i o n a l ~ T a i w a n ~ U n i v e r s i t y, ~}$ \\ ${ }^{f}$ Division of Pulmonary Medicine, Department of Internal Medicine, National Taiwan University Hospital, and College of Medicine, \\ National Taiwan University, \\ ${ }^{9}$ Department of Physiology, College of Medicine, National Taiwan University, Taipei, Taiwan
}

\section{Keywords}

Postmenopausal women - Myocardial perfusion .

${ }^{201} \mathrm{TI}$ SPECT · Exercise - Overweight · Cardiac function

\section{Summary}

Objective: This study aimed to investigate whether physical inactivity and overweight deteriorate myocardial perfusion and cardiac function in asymptomatic postmenopausal women. Methods: A prospective cross-sectional study design was used. Postmenopausal women recruited in this study were categorized into groups based on activity level and BMI: physically active, normal-weight group (PANw, $\mathrm{n}=15,60.9 \pm 6.0$ years), physically inactive, normal-weight group (PIANw, $\mathrm{n}=$ $13,57.2 \pm 5.0$ years) and physically inactive, overweight group ( $\mathrm{PIAO}, \mathrm{n}=26,58.5 \pm 5.8$ years). Each subject took cardiopulmonary function tests and ECG-gated exercise ${ }^{201} \mathrm{TI}$ myocardial perfusion imaging (MPI). Perfusion abnormalities, cardiac function indices, and ${ }^{201} \mathrm{TI}$ lungto-heart ratio (LHR) were derived. Results: The PIANw women had lower exercise capacity than PANw women. More subjects in PIANw (46\%) or PIAO (48\%) groups had worsening in left ventricular ejection fraction (LVEF) by exercise than subjects in PANw $(7 \%)$ group. The PIAO women exhibited significantly lower exercise capacity and higher rest LHR than PANw women (LHR $0.41 \pm$ 0.05 vs. $0.36 \pm 0.06 ; p=0.014)$. Abnormal MPI tended to increase in PIANw (38\%) and PIAO (46\%) women when compared with the PANw (27\%) group. Conclusions: Physically inactive, overweight postmenopausal women had higher rest ${ }^{201} \mathrm{TI}$ lung uptake and worsening LVEF by exercise and tended to have higher prevalence of inducible ischemia, suggesting higher cardiovascular risks although asymptomatic.

\section{Introduction}

The prevalence and incidence of coronary artery disease (CAD) in women increases dramatically after menopause and is the leading cause of mortality among postmenopausal women [1]. The atypical symptoms and signs, the high prevalence of non-obstructive CAD, and single vessel disease increase the challenges of diagnostic and prognostic testing in women [2]. However, women with similar severity of CAD have tended to receive less intensive evaluations and treatment than men $[3,4]$. This might result in a subsequently worse prognosis than in men [5]. The early detection of CAD and accurate risk stratification provide optimization of subject outcome. Exercise myocardial perfusion imaging (MPI) by thallium-201 single photon emission computed tomography $\left({ }^{201} \mathrm{Tl} \mathrm{SPECT}\right)$ has been shown to be useful in risk stratifica-

\section{KARGER \\ Fax +497614520714 \\ Information@Karger.de}

www.karger.com

\section{(c) 2011 S. Karger GmbH, Freiburg}

$1662-4025 / 11 / 0045-0372 \$ 38.00 / 0$

Accessible online at:

www.karger.com/ofa
Dr. Ying-Tai Wu, Ph. D.

School and Graduate Institute of Physical Therapy

College of Medicine, National Taiwan University

Floor 3, No. 17, Xuzhou Road, Zhongzheng District, Taipei City 100, Taiwan (R.O.C.)

Tel. +886 2 3366-8129, Fax -8161

ytw@ntu.edu.tw 
tion for future cardiac events in postmenopausal women [6, 7]. There was a nearly one fifth rate of myocardial perfusion defects in asymptomatic elderly women, and the rate of abnormal scans was even higher in those with elevated CAD risks [8].

Obesity or physical inactivity listed as CAD risks in the latest guidelines in women for cardiovascular disease prevention [2]. Research has been reported obesity or overweight not only associated with increased cardiovascular risks but also cardiac dysfunction in people without CAD [9]. Little is known about the influences of physical inactivity on the myocardial perfusion or cardiac function in asymptomatic postmenopausal women, although the benefits of physical activity on decreasing incidence and mortality of cardiovascular disease have been proved [2]. These two risks are noted high in prevalence and often co-existed in postmenopausal women [1]. This study was thus designed to determine the separate or combined effects of physical inactivity and overweight status on myocardial perfusion, cardiac function as well as cardiopulmonary fitness in asymptomatic postmenopausal women.

\section{Participants and Methods}

\section{Participants}

A prospective, cross-sectional study design was applied. A total of 60 volunteers were recruited through advertising in the hospital nearby communities. Subjects were included if they were postmenopausal (no menstruation after natural menopause for at least 12 months) and without any signs or symptoms suggesting heart disease (including CAD, congenital or valvular heart disease, myocarditis, or idiopathic cardiomyopathy) or peripheral artery disease. They were excluded if they had current use of hormone replacement therapy, impaired renal function (serum creatinine $\geq 1.5 \mathrm{mg} / \mathrm{dl}$ ) or liver function (total bilirubin $\geq 2 \mathrm{mg} / \mathrm{dl}$, alanine aminotransferase $\geq 2 \times$ upper limit of the normal range), abnormal resting electrocardiogram (ECG), active pulmonary disease, weight loss $>10 \mathrm{~kg}$ in the past 6 months, or any ongoing or unstable medical conditions. This study was reviewed and approved by National Taiwan University Hospital Ethics Committee. Written informed consent was obtained before the testing.

All subjects had low Framingham Risk Score (FRS), the 10-year risk of developing CAD was $2.2 \pm 1.6 \%$ (range $1-7 \%$ ) [2, 10]. Participants were considered physically active (PA) if they performed moderateintensity aerobic physical activity for a minimum of $30 \mathrm{~min} 5$ days a week or vigorous activity for a minimum of $20 \mathrm{~min} 3$ days a week [11]. Otherwise, they were considered physically inactive (PIA) as suggested by the Guidelines of Physical Activities for Adults of the American Heart Association and the American College of Sports Medicine. The participants were classified into a normal-weight or an overweight group according to the national overweight criteria: BMI between $18.5-23.9 \mathrm{~kg} / \mathrm{m}^{2}$ is considered as normal weight, while $\mathrm{BMI} \geq 24 \mathrm{~kg} / \mathrm{m}^{2}$ is considered as overweight [12]. Combining physical activity levels with BMI categories, all participants were classified into physically active, normal-weight (PANw, $\mathrm{n}=15$ ), physically active, overweight (PAO, $\mathrm{n}=6)$, physically inactive, normalweight (PIANw, $\mathrm{n}=13$ ), and physically inactive overweight (PIAO, $\mathrm{n}=26$ ) groups.

Medical history and clinical characteristics were obtained, and all participants underwent a physical examination, blood drawn for laboratory tests, cardiopulmonary exercise testing, and exercise ${ }^{201} \mathrm{Tl}$ SPECT within 1 week.

\section{Anthropometric Measurement}

Body weight $(\mathrm{kg})$ and body height $(\mathrm{cm})$ were measured with subjects standing barefoot and with light clothes. Waist circumference $(\mathrm{cm})$ was measured at the middle line between the lower chest and iliac crest.

\section{Laboratory Tests}

A venous blood sample was taken after 8-hour fasting for measuring fasting plasma glucose, $\mathrm{HbA}_{1} \mathrm{c}$, total cholesterol, high-density lipoprotein cholesterol (HDL-C), low-density lipoprotein cholesterol (LDL-C), triglyceride, and C-reactive protein (CRP).

\section{Cardiopulmonary Exercise Testing}

Cardiopulmonary fitness was assessed by measuring peak oxygen uptake with treadmill according to the Bruce protocol. The resting heart rate (HR) and blood pressure were measured after at least 3 min of rest. Each participant performed a maximum exercise test with continuous ECG monitoring. Respiratory gas exchange variables were determined on a breath-by-breath basis and averaged over a 30-second interval with a Vmax Series V229 gas analyzer (Vmax229, Sensor Medics, Anaheim, CA, USA). The system was calibrated using a fixed standard gas concentration before each test. Peak oxygen consumption (peak $\mathrm{VO}_{2}$ ) was determined from the average value of oxygen consumption over the final $30 \mathrm{~s}$ of the exercise test. The termination criteria included at least two of the following criteria: signs or symptoms of exercise intolerance (such as physical exhaustion, volitional fatigue or dyspnea), $\geq 90 \%$ of age-predicted maximum HR (=220 - age), respiratory exchange ratio $\geq 1.15$, or abnormal ECG.

After achieving peak workload, the treadmill was stopped without a cool-down period, and the participant remained in a seated position for a recovery period of 2 or more min. Heart rate recovery 1 (HRR1) or heart rate recovery 2 (HRR2) were defined as the decreases in heart rate between peak exercise and $1 \mathrm{~min}$ or $2 \mathrm{~min}$ in the recovery period, respectively.

\section{ECG-Gated ${ }^{201}$ Tl SPECT}

Standard treadmill ${ }^{201} \mathrm{Tl}$ SPECT testing was performed according to the guidelines from the American Society of Nuclear Cardiology and the American Heart Association [13] within 1 week after the cardiopulmonary function test. Bruce exercise protocol with continuous 12-lead ECG and blood pressure monitoring was used. A 3-3.5 mCi dose of ${ }^{201} \mathrm{Tl}$ was injected intravenously near the time of maximal stress levels; after the injection, exercise continued for one additional minute. Post-stress images were acquired within 5 min after ${ }^{201} \mathrm{Tl}$ injection and redistribution images were acquired 3-3.5 h later.

ECG-gated ${ }^{201}$ Tl SPECT ( 8 frames per cardiac cycle) was acquired on a dual-head SPECT/CT scanner (Symbia T2, Siemens Medical Solution Inc., Hoffman Estates, IL, USA) equipped with low-energy general purpose collimators and 2-slice CT, using a circular $180^{\circ}$ acquisition for 64 projections at 20 (post-stress) and 25 (rest) s/projection. The SPECT data were stored in a $128 \times 128$ matrix. All projection images were transferred in DICOM format, and processed using syngo MI applications. Breath-hold CT was performed after the post-stress emission acquisition using parameters as follows: tube rotation time, $0.8 \mathrm{~s} /$ revolution (total scan time in about $10 \mathrm{~s}$ ); $130 \mathrm{kV} ; 17 \mathrm{~mA} ; 5 \mathrm{~mm} /$ rotation; and slice pitch of 1.5 [14]. CT images were reconstructed onto a $512 \times 512$ matrix. Matched CT and SPECT image were reconstructed with a field of $50 \mathrm{~cm}$ in $5-\mathrm{mm}$ slice thickness. Emission data were reconstructed iteratively with CT-derived attenuation correction using ordered-subset expectation maximization. The non-corrected and attenuation-corrected images, along with accompanying ECG-gated SPECT images, were presented for blinded consensus interpretation.

\section{SPECT Analysis}

The quality of gated data was reviewed after acquisition. Quantitative Gated SPECT (QGS) and Quantitative Perfusion SPECT (QPS) software (Cedars-Sinai Medical Center, Los Angeles, CA, USA) were used 
Table 1. Clinical characteristics of subjects

\begin{tabular}{|c|c|c|c|c|}
\hline & $\begin{array}{l}\text { PANw } \\
(\mathrm{n}=15)\end{array}$ & $\begin{array}{l}\text { PIANw } \\
(\mathrm{n}=13)\end{array}$ & $\begin{array}{l}\text { PIAO } \\
(\mathrm{n}=26)\end{array}$ & $\mathrm{p}$ value \\
\hline Age, years & $60.9 \pm 6.0$ & $57.2 \pm 5.0$ & $58.5 \pm 5.8$ & 0.218 \\
\hline Menopausal age, years & $50.1 \pm 5.5$ & $48.6 \pm 7.3$ & $49.0 \pm 4.2$ & 0.754 \\
\hline Body height, cm & $156.4 \pm 5.4$ & $156.3 \pm 5.5$ & $155.9 \pm 4.6$ & 0.946 \\
\hline Body weight, $\mathrm{kg}$ & $53.2 \pm 5.8$ & $53.1 \pm 3.9$ & $66.1 \pm 8.2 * \dagger$ & $<0.001$ \\
\hline $\mathrm{BMI}, \mathrm{kg} / \mathrm{m}^{2}$ & $21.7 \pm 1.6$ & $21.2 \pm 1.1$ & $27.2 \pm 2.9 * \dagger$ & $<0.001$ \\
\hline Waist circumference, $\mathrm{cm}$ & $74.3 \pm 5.1$ & $73.6 \pm 4.3$ & $87.9 \pm 8.1 * \dagger$ & $<0.001$ \\
\hline \multicolumn{5}{|l|}{ Comorbidities (\%) } \\
\hline Hypertension & $9(60 \%)$ & $8(62 \%)$ & $16(62 \%)$ & 0.995 \\
\hline Dyslipidemia & $6(40 \%)$ & $3(23 \%)$ & $11(42 \%)$ & 0.414 \\
\hline Diabetes mellitus & $5(33 \%)$ & $6(46 \%)$ & $13(50 \%)$ & 0.580 \\
\hline \multicolumn{5}{|l|}{ Medication (\%) } \\
\hline ACEI or ARB & $4(27 \%)$ & $2(15 \%)$ & $8(31 \%)$ & 0.584 \\
\hline Beta blocker & $2(7 \%)$ & $1(8 \%)$ & $2(8 \%)$ & 0.815 \\
\hline Calcium channel blockers & $1(13 \%)$ & $1(8 \%)$ & $6(23 \%)$ & 0.257 \\
\hline Diuretics & $1(13 \%)$ & $1(8 \%)$ & $4(15 \%)$ & 0.627 \\
\hline Statins & $5(33 \%)$ & $3(23 \%)$ & $5(19 \%)$ & 0.593 \\
\hline OHA & $4(27 \%)$ & $6(46 \%)$ & $11(42 \%)$ & 0.507 \\
\hline \multicolumn{5}{|l|}{ Glycemic control } \\
\hline Fasting glucose, mg/dl & $109.8 \pm 23.9$ & $104.5 \pm 20.8$ & $120.6 \pm 36.5$ & 0.277 \\
\hline $\mathrm{HbA}_{1} \mathrm{c}, \%$ & $6.4 \pm 1.0$ & $6.4 \pm 1.0$ & $6.7 \pm 1.2$ & 0.681 \\
\hline Total cholesterol, mg/dl & $195.1 \pm 32.0$ & $190.0 \pm 27.7$ & $212.0 \pm 36.5$ & 0.122 \\
\hline HDL-C, mg/dl & $59.5 \pm 12.7$ & $50.6 \pm 11.3$ & $50.7 \pm 8.5$ & 0.036 \\
\hline LDL-C, mg/dl & $101.9 \pm 23.7$ & $105.2 \pm 27.9$ & $119.7 \pm 27.8$ & 0.085 \\
\hline Triglyceride, mg/dl & $92.1 \pm 33.2$ & $130.6 \pm 92.5$ & $151.5 \pm 75.2$ & 0.047 \\
\hline CRP, mg/dl & $0.09 \pm 0.10$ & $0.13 \pm 0.18$ & $0.43 \pm 0.47 \dagger$ & 0.011 \\
\hline
\end{tabular}

PANw = Physically active, normal weight PIANw = physically inactive, normal weight; $\mathrm{PIAO}=$ physically inactive, overweight; $\mathrm{ACEI}=$ angiotensin-converting enzyme inhibitors; $\mathrm{ARB}=$ angiotensin II receptor blockers; OHA = oral hypoglycemic agents.

$* \mathrm{p}<0.02$ compared between PIANw and PIAO groups after Bonferroni post-hoc analysis. $\dagger \mathrm{p}<0.02$ compared between PANw and PIAO groups after Bonferroni post-hoc analysis.

in full automatic processing mode without manual interaction [15]. The diagnostic performance of this quantitation software was confirmed in previous study [16] with excellent intra- and inter-reader reproducibility in our institute $(r \geq 0.99)$ [17]. Quantitative programs aided the assessment of regional wall motion as well as the calculation of left ventricular ejection fraction (LVEF) and stroke volume (SV). The change of the LVEF by exercise was also calculated. A worsening in LVEF by exercise was considered abnormal [18]. The left ventricular SV was normalized with body surface area and presented as the SV index. Non-gated images for assessment of ${ }^{201} \mathrm{Tl}$ uptake were obtained by summing all gated images. The myocardium was divided into a 20-segment model [19], and myocardial perfusion was graded using a standard 5-point scoring system $(0=$ normal uptake of the radioactive isotope; $1=$ slight reduction of uptake; 2 moderate reduction of uptake; $3=$ severe reduction of uptake; $4=$ absence of uptake) for each segment. The segmental perfusion scores during stress and at rest were added to create the summed stress scores (SSS) and the summed rest scores (SRS), respectively. The summed difference score (SDS) was the difference between SSS and SRS, indicating the extent of ischemia. The extent of ischemia was expressed as \% myocardium ischemic $(\%$ myocardium ischemic $=\mathrm{SDS} / 80 \times 100):<2.5 \%$ myocardium ischemic was considered nonischemic; $2.5-7.4 \%$ myocardium ischemic as a small to moderate extent of ischemia; $\geq 7.5 \%$ myocardium ischemic as a large extent of ischemia [20]. In this study, none of subjects had history of myocardial infarction, and abnormal MPI was defined as the ischemic myocardium $\geq 2.5 \%$. Non-perfusion abnormalities, including transient left ventricular dilatation, ischemic ECG changes, and ${ }^{201} \mathrm{Tl}$ lung-to-heart ratio (the ratio between lung uptake and myocardial uptake of ${ }^{201} \mathrm{Tl}$ ) were also assessed. Two experienced readers who were blinded to patients' clinical information and results of cardiopulmonary test participated in this study. In the event that the 2 interpretations did not agree with one another, the image was re-evaluated by the 2 physicians until a consensus was reached.

\section{Data Analysis and Statistics}

All statistical analyses were performed using SPSS 13.0 statistical software (SPSS Inc., Chicago, IL, USA). All continuous variables were displayed as the mean \pm standard deviation. Subjects who were physically active but overweight (Group PAO) were excluded because of the small sample size $(n=6)$. With priori effect size and power calculation, the sample size of other 3 groups were adequate for statistical analysis. One-way ANOVA with Bonferroni post-hoc analysis was performed to make pairwise comparisons among groups. Non-parametric tests, chi-square tests, or Fisher exact measures were used for categorical variables. An adjusted $\mathrm{p}$ value $<0.02$ was considered significant.

\section{Results}

All participants were non-smokers aged between 48 and 70 years. No significant differences in basic and clinical characteristics were noted, except higher body weight, BMI, and 
Table 2. Cardiopulmonary exercise performance

Table 3. Results of ECG-gated ${ }^{201} \mathrm{Tl}$ SPECT

\begin{tabular}{|c|c|c|c|c|}
\hline & $\begin{array}{l}\text { PANw } \\
(\mathrm{n}=15)\end{array}$ & $\begin{array}{l}\text { PIANw } \\
(\mathrm{n}=13)\end{array}$ & $\begin{array}{l}\text { PIAO } \\
(\mathrm{n}=26)\end{array}$ & $\mathrm{p}$ value \\
\hline Resting heart rate, bpm & $67.2 \pm 8.9$ & $75.5 \pm 7.8$ & $73.8 \pm 9.1$ & 0.030 \\
\hline \multicolumn{5}{|c|}{ Resting blood pressure, $\mathrm{mm} \mathrm{Hg}$} \\
\hline Systolic & $122.9 \pm 11.9$ & $123.1 \pm 17.0$ & $126.7 \pm 15.3$ & 0.672 \\
\hline Diastolic & $75.5 \pm 8.6$ & $78.1 \pm 10.6$ & $78.9 \pm 10.0$ & 0.551 \\
\hline Peak heart rate, bpm & $143.0 \pm 13.8$ & $142.5 \pm 13.3$ & $135.8 \pm 16.3$ & 0.240 \\
\hline \multicolumn{5}{|c|}{ Peak blood pressure, $\mathrm{mm} \mathrm{Hg}$} \\
\hline Systolic & $177.8 \pm 15.9$ & $171.1 \pm 23.4$ & $182.5 \pm 20.9$ & 0.260 \\
\hline Diastolic & $86.3 \pm 12.0$ & $87.0 \pm 11.0$ & $87.7 \pm 14.4$ & 0.946 \\
\hline \multicolumn{5}{|c|}{ Peak oxygen consumption (peak $\mathrm{VO}_{2}$ ) } \\
\hline $\mathrm{ml} \mathrm{O}_{2} / \mathrm{kg} / \mathrm{min}$ & $23.0 \pm 4.7$ & $20.3 \pm 2.9$ & $18.7 \pm 2.4 \dagger$ & 0.001 \\
\hline$\%$ of predicted & $89.5 \pm 14.8$ & $76.3 \pm 7.6 \ddagger$ & $70.6 \pm 8.3 \dagger$ & $<0.001$ \\
\hline HRR1, bpm & $31.1 \pm 10.5$ & $28.2 \pm 7.2$ & $28.0 \pm 10.5$ & 0.585 \\
\hline HRR2, bpm & $51.5 \pm 13.0$ & $44.4 \pm 8.4$ & $42.4 \pm 11.4$ & 0.048 \\
\hline
\end{tabular}

PANw $=$ Physically active, normal weight PIANw = physically inactive, normal weight; PIAO = physically inactive, overweight; HRR 1 = heart rate recovery 1 , which is defined as the decrease in heart rate between peak exercise and $1 \mathrm{~min}$ in the recovery; HRR2 = heart rate recovery 2 , which is defined as the decrease in heart rate between peak exercise and $2 \mathrm{~min}$ in the recovery.

$\dagger \mathrm{p}<0.02$ compared between PANw and PIAO groups after Bonferroni post-hoc analysis. $\$ \mathrm{p}<0.02$ compared between PANw and PIANw groups after Bonferroni post-hoc analysis.

\begin{tabular}{|c|c|c|c|c|}
\hline & $\begin{array}{l}\text { PANw } \\
(\mathrm{n}=15)\end{array}$ & $\begin{array}{l}\text { PIANw } \\
(\mathrm{n}=13)\end{array}$ & $\begin{array}{l}\text { PIAO } \\
(\mathrm{n}=26)\end{array}$ & $\mathrm{p}$ value \\
\hline \multicolumn{5}{|l|}{ Quantitative perfusion SPECT } \\
\hline Summed stress score & $4.9 \pm 4.3$ & $6.5 \pm 7.4$ & $4.4 \pm 4.2$ & 0.888 \\
\hline Summed rest score & $2.3 \pm 3.4$ & $1.9 \pm 2.2$ & $1.1 \pm 2.0$ & 0.332 \\
\hline Summed difference score & $2.4 \pm 2.0$ & $4.4 \pm 5.6$ & $3.2 \pm 2.4$ & 0.727 \\
\hline \multicolumn{4}{|l|}{ Extent of ischemic myocardium (\%) } & 0.467 \\
\hline $2.5 \sim 7.4 \%$ & $4(27 \%)$ & $1(7 \%)$ & $8(31 \%)$ & \\
\hline$\geq 7.5 \%$ & 0 & $4(31 \%)$ & $4(15 \%)$ & \\
\hline \multicolumn{5}{|l|}{${ }^{201} \mathrm{Tl}$ lung-to-heart ratio } \\
\hline Rest & $0.36 \pm 0.06$ & $0.35 \pm 0.05$ & $0.41 \pm 0.05 \dagger$ & 0.004 \\
\hline Stress & $0.33 \pm 0.08$ & $0.31 \pm 0.04$ & $0.36 \pm 0.06$ & 0.121 \\
\hline \multicolumn{5}{|l|}{ Quantitative Gated SPECT } \\
\hline \multicolumn{5}{|l|}{ Ejection fraction, \% } \\
\hline Rest & $79.3 \pm 10.4$ & $80.9 \pm 9.5$ & $81.2 \pm 10.2^{\mathrm{a}}$ & 0.846 \\
\hline Post-stress & $83.8 \pm 12.1$ & $80.7 \pm 10.2$ & $82.3 \pm 8.2^{\mathrm{a}}$ & 0.714 \\
\hline Decrease in ejection fraction (\%) & $1(7 \%)$ & $6(46 \%) \ddagger$ & $12(48 \%) \dagger$ & 0.021 \\
\hline \multicolumn{5}{|l|}{ Stroke volume index, $\mathrm{ml} / \mathrm{m}^{2}$} \\
\hline Rest & $25.2 \pm 4.4$ & $24.8 \pm 3.0$ & $22.4 \pm 7.4^{\mathrm{a}}$ & 0.281 \\
\hline Post-stress & $25.0 \pm 6.8$ & $23.0 \pm 5.2$ & $20.8 \pm 8.0^{\mathrm{a}}$ & 0.161 \\
\hline \multicolumn{5}{|c|}{$\begin{array}{l}\text { PANw = Physically active, normal weight; PIANw = physically inactive, normal weight; } \\
\text { PIAO = physically inactive, overweight. } \\
\dagger \mathrm{p}<0.02 \text { compared between PANw and PIAO groups after post-hoc analysis. } \\
\mathrm{t} \mathrm{p}<0.02 \text { compared between PANw and PIANw groups after post-hoc analysis. } \\
{ }^{a} \mathrm{n}=25 \text {, gated SPECT did not performed in one postmenopausal woman. }\end{array}$} \\
\hline
\end{tabular}

waist circumference in the PIAO group than in the other subjects (table 1). All subjects underwent cardiopulmonary function testing and treadmill ${ }^{201} \mathrm{Tl}$ SPECT without discomfort and adverse events (table 2,3). No participants had regional wall motion abnormalities on ECG-gated ${ }^{201} \mathrm{Tl}$ SPECT, but there was an overall 39\% prevalence of abnormal SPECTbased myocardial perfusion in the asymptomatic postmenopausal women in our study. Abnormal MPI was noted in $4(27 \%)$ of PANw, 5 (38\%) of PIANw, and $12(46 \%)$ of PIAO women (table 3 ), many of them were defined as mild ischemia. 
According to the 20-segment analysis, the ischemic territories were located in left anterior descending, circumflex and right coronary arteries in 12 (22\%), 14 (26\%) and 11 (20\%) participants, respectively.

\section{The Effects of Physical Inactivity in Women with Normal Weight (PANw vs. PIANw)}

The inactive normal-weight women had a lower exercise capacity level than their active counterparts (table 2). Higher but nonsignificant resting HR was noted in the PIANw group after Bonferroni post-hoc analysis $(\mathrm{p}<0.05)$. The quantitative perfusion and gated SPECT analyses and ${ }^{201} \mathrm{Tl}$ lung-to-heart ratios were not significantly different between two groups. However, higher prevalence of subjects in PIANw group had worsening LVEF by exercise than those in the PANw group (46\% vs. $7 \%$; table 3 ).

\section{The Effects of Overweight Status in Physically Inactive Women (PIAO vs. PIANw)}

The clinical characteristics and exercise capacity were similar between PIAO and PIANw groups (table 1, 2). Resting ${ }^{201} \mathrm{Tl}$ lung-to-heart ratio of PIAO group was slightly higher than that of the PIANw group $(\mathrm{p}=0.021)$ (table 3$)$.

\section{Combined Effects of Physical Inactivity and Overweight Status (PIAO vs. PANw)}

In comparison to the PANw group, the PIAO group exhibited a higher CRP level $(\mathrm{p}=0.017)$, a lower peak $\mathrm{VO}_{2}(\mathrm{p}=0.001)$ (table 1, 2), and a higher resting ${ }^{201} \mathrm{Tl}$ lung-to-heart ratio $(p=0.014)$. Significantly more subjects in the PIAO group had a worsening LVEF by exercise than subjects in the PANw group (table 3 ). Although lower HDL-C, higher triglyceride levels, and slower heart rate recovery (all $\mathrm{p}<0.05)$ were also noted in the PIAO group when compared with PANw group, the significance levels became nonsignificant by Bonferroni post-hoc analysis.

\section{Discussion}

After menopause, physically inactive normal-weight women had a higher resting HR, lower exercise capacity and worsening LVEF by exercise than physically active women. Postmenopausal women in overweight status had higher resting ${ }^{201} \mathrm{Tl}$ lung-to-heart ratio. Furthermore, the prevalence of abnormal myocardial perfusion tended to be higher in inactive overweight women.

\section{The Effects of Physical Inactivity in Women with Normal Weight}

In women with normal body weight, we found a higher resting HR in physically inactive women compared than in physically active women. A higher resting HR represents a higher sympathetic tone associated with cardiac risk factors such as ab- normal blood pressure, adverse lipid profile, and impaired glucose metabolism [21]. Hsia and coworkers [21] suggested that resting HR could predict coronary events and stroke in postmenopausal women. Our results suggested that physical activity ameliorates the deteriorating effects of sympathetic activity in postmenopausal women. A low fitness level was noted in the physically inactive group with normal weight in this study; this low fitness level might increase cardiovascular disease morbidity in postmenopausal women [22]. In addition, a slightly smaller, but nonsignificant SV index was noted in the inactive women group. Treadmill ECG-gated SPECT showed that about half of the inactive women had worsening LVEF by exercise, whether overweight or not. Previous studies suggested that the worsening LVEF after stress is an indicator of left ventricular systolic dysfunction and have a correlation with CAD [18, 23]. The decline in SV index after exercise and more subjects with worsening LVEF after exercise might partially explain lower exercise capacity in inactive women. Regular physical activity might improve the cardiovascular health in postmenopausal women [24, 25].

\section{The Effects of Overweight Status in Physically Inactive Women}

The incidence of overweight status and obesity continues to increase worldwide. The BMI has been shown to be an important predictor of cardiovascular diseases in some studies $[1,26]$, while other investigators reported that overweight status and obesity was not associated with abnormal SPECT $[27,28]$. However, these studies comprised predominately male subjects who were either symptomatic or suggestive of CAD. Our study in inactive postmenopausal women who were asymptomatic with low FRS demonstrated that the overweight subjects tended to have a higher rate of abnormal MPI, an independent predictor of future fatal or nonfatal cardiac events [20], compared to subjects with normal weight.

In the present study, PIAO women had higher resting ${ }^{201} \mathrm{Tl}$ lung-to-heart ratio. The loading of overweight on the respiratory system might affect lung volumes and cardiac function [29] and result in higher ${ }^{201} \mathrm{Tl}$ lung uptake. In addition, an elevated ${ }^{201} \mathrm{Tl}$ lung-to-heart ratio has been used as an index of severity and extents of coronary heart disease [30, 31]. High ${ }^{201} \mathrm{Tl}$ lung uptake without significant perfusion defects might suggest diffuse microvascular disease.

\section{Combined Effects of Physical Inactivity and Overweight Status in Postmenopausal Women}

Higher levels of CRP and lower levels of fitness were noted in the PIAO group when compared with the PANw group which was considered to have minimized the risk of CAD as much as possible. Compared to PANw women, the PIAO women were prone to exhibit a more adverse lipid profile and a slower heart rate recovery. Previous evidence has supported that both elevated inflammation markers and unfavorable lipid profile accounted for the increased risks of CAD [2]. A 
slow heart rate recovery was demonstrated to have a relationship with risk factors or prognostic predictors of CAD in postmenopausal women [2].

Taken together, asymptomatic postmenopausal women in inactivity and overweight status tended to have higher prevalence of inducible ischemia and worsening LVEF by exercise, higher rest ${ }^{201} \mathrm{Tl}$ lung uptake, and more cardiovascular risk factors, suggesting higher risks of cardiovascular complication even if they are under adequate metabolic control and showed a low FRS.

There were several limitations of this study. The sample size was rather small. Self-referral bias might be present and limit the generalization because the subjects were volunteers from hospital nearby communities. Although there was a similar prevalence of diabetes and hypertension in the study groups, the high prevalence of comorbidities that were being treated might complicate the interpretation of the results. Physically active overweight women could not be recruited in sufficient numbers; thus they were excluded from analysis. In addition, the study had a cross-sectional design, and the causal relationship could not be inferred. In this study we examined the effect of overweight, but not obesity, on the myocardial perfusion and cardiac function. The role of overweight versus obesity as a risk factor needs to be clarified. Future studies with a larger scale and long-term follow-up may help to support our hypothesis.

${ }^{201} \mathrm{Tl}$ labelled tracers instead of those labeled with ${ }^{99 \mathrm{~m}} \mathrm{Tc}$ labelled were used in the study. ${ }^{201} \mathrm{Tl}$ tracers are widely used in Asian countries, including Taiwan. Despite the low myocardial count densities and a large amount of scattered photons $[15,32]$, previous studies have demonstrated that the performance of ${ }^{201} \mathrm{Tl}$ not only was comparable with that of ${ }^{99 \mathrm{~m}} \mathrm{Tc}$ sestamibi in myocardial perfusion and cardiac function [13, 33, 34], but also showed a high accuracy in CAD detection [33]. Although women might have breast attenuation in the anterior wall by using SPECT [35], soft tissue attenuation artifacts as a source of perfusion defects has been reported less frequently in Asian populations $[18,36]$. In addition to gated SPECT, CT attenuation correction was used to further improve the quality of images in the present study. Recent evidence showed that attenuation correction resulted in less equivocal images and improved risk stratification [37,38], including obese subjects [39]. Finally, no invasive coronary angiography was performed since all subjects were asymptomatic and the majority of perfusion abnormalities was mild; therefore, optimized medical therapy and regular follow-up have been the first recommended [40].

\section{Conclusions}

In postmenopausal women with normal body weight, the physically inactive ones tended to have abnormal myocardial perfusion on SPECT, despite asymptomatic and low FRS. Worsening LVEF by exercise was noted in the physically inactive women whether overweight or not. Overweight status increased ${ }^{201} \mathrm{Tl}$ lung uptake which could be associated with adverse cardiac outcomes, even under adequate medical therapy.

\section{Acknowledgments}

The authors would like to thank the National Science Council of the Republic of China, Taiwan, for financially supporting this research under Contract No. NSC 98-2314-B-002-014-MY3.

\section{Disclosure Statement}

The authors declared no conflict of interest.

\section{References}

1 Rosamond W, Flegal K, Friday G, Furie K, Go A, Greenlund K, Haase N, Ho M, Howard V, Kissela B, Kittner S, Lloyd-Jones D, McDermott M, Meigs J, Moy C, Nichol G, O'Donnell CJ, Roger V, Rumsfeld J, Sorlie P, Steinberger J, Thom T, WasserthielSmoller S, Hong Y: Heart disease and stroke statistics - 2007 update: a report from the American Heart Association Statistics Committee and Stroke Statistics Subcommittee. Circulation 2007;115:e69-171.

2 Mosca L, Banka CL, Benjamin EJ, Berra K, Bushnell C, Dolor RJ, Ganiats TG, Gomes AS, Gornik HL, Gracia C, Gulati M, Haan CK, Judelson DR, Keenan N, Kelepouris E, Michos ED, Newby LK, Oparil S, Ouyang P, Oz MC, Petitti D, Pinn VW, Redberg RF, Scott R, Sherif K, Smith SC Jr, Sopko G, Steinhorn RH, Stone NJ, Taubert KA, Todd BA, Urbina E, Wenger NK: Evidence-based guidelines for cardiovascular disease prevention in women: 2007 update. J Am Coll Cardiol 2007;49: $1230-1250$.
3 Hachamovitch R, Berman DS, Kiat H, BaireyMerz N, Cohen I, Cabico JA, Friedman JD, Germano G, Van Train KF, Diamond GA: Genderrelated differences in clinical management after exercise nuclear testing. J Am Coll Cardiol 1995;26: 1457-1464.

4 Sanderson BK, Shewchuk RM, Bittner V: Cardiac rehabilitation and women: what keeps them away? J Cardiopulm Rehabil Prev 2010;30:12-21.

$\checkmark 5$ Wenger NK, Speroff L, Packard B: Cardiovascular health and disease in women. N Engl J Med 1993; 329:247-256.

6 Valeti US, Miller TD, Hodge DO, Gibbons RJ: Exercise single-photon emission computed tomography provides effective risk stratification of elderly men and elderly women. Circulation 2005;111: 1771-1776.
7 Mieres JH, Makaryus AN, Cacciabaudo JM, Donaldson D, Green SJ, Heller GV, Maddahi J, Ong L, Rampersaud T, Rosen SE, Shaw LJ, Katz S: Value of electrocardiographically gated single-photon emission computed tomographic myocardial perfusion scintigraphy in a cohort of symptomatic postmenopausal women. Am J Cardiol 2007;99: 1096-1099.

8 Lee SJ, Lee KH, Park SM, Lee EJ, Chung HW, Cho YS, Choi JY, Kim BT: Myocardial perfusion defects and coronary risk factors in symptomatic and asymptomatic elderly women. Int J Cardiovasc Imaging 2008;24:277-281.

9 Powell BD, Redfield MM, Bybee KA, Freeman WK, Rihal CS: Association of obesity with left ventricular remodeling and diastolic dysfunction in patients without coronary artery disease. Am J Cardiol 2006;98:116-120. 
10 Third Report of the National Cholesterol Education Program (NCEP) Expert Panel on Detection, Evaluation, and Treatment of High Blood Cholesterol in Adults (Adult Treatment Panel III) final report. Circulation 2002;106:3143-3421.

11 American College of Sports Medicine: ACSM's Guidelines for Exercise Testing and Prescription, 8th ed. Philadelphia, Lippincott Williams \& Wilkins: 2010.

12 Department of Health, Executive Yuan. R.O.C. (Taiwan). Available at www.doh.gov.tw, accessed on April 1, 2010.

13 Klocke FJ, Baird MG, Lorell BH, Bateman TM, Messer JV, Berman DS, O'Gara PT, Carabello BA. Russell RO Jr, Cerqueira MD, St John Sutton MG, DeMaria AN, Udelson JE, Kennedy JW, Verani MS, Williams KA, Antman EM, Smith SC Jr, Alpert JS, Gregoratos G, Anderson JL, Hiratzka LF, Faxon DP, Hunt SA, Fuster V, Jacobs AK, Gibbons RJ, Russell RO: ACC/AHA/ASNC guidelines for the clinical use of cardiac radionuclide imaging - executive summary: a report of the American College of Cardiology/American Heart Association Task Force on Practice Guidelines (ACC/AHA/ ASNC Committee to Revise the 1995 Guidelines for the Clinical Use of Cardiac Radionuclide Imaging). J Am Coll Cardiol 2003;42:1318-1333.

14 Schepis T, Gaemperli O, Koepfli P, Ruegg C, Burger C, Leschka S, Desbiolles L, Husmann L, Alkadhi H, Kaufmann PA: Use of coronary calcium score scans from stand-alone multislice computed tomography for attenuation correction of myocardial perfusion SPECT. Eur J Nucl Med Mol Imaging 2007;34:11-19.

15 Germano G, Kavanagh PB, Slomka PJ, Van Kriekinge SD, Pollard G, Berman DS: Quantitation in gated perfusion SPECT imaging: the CedarsSinai approach. J Nucl Cardiol 2007;14:433-454.

16 Wolak A, Slomka PJ, Fish MB, Lorenzo S, Acampa W, Berman DS, Germano G: Quantitative myocardial-perfusion SPECT: comparison of three state-of-the-art software packages. J Nucl Cardiol 2008;15:27-34.

17 Wang SY, Cheng MF, Hwang JJ, Hung CS, Wu YW: Sex-specific normal limits of left ventricular ejection fraction and volumes estimated by gated myocardial perfusion imaging in adult patients in Taiwan: a comparison between two quantitative methods. Nucl Med Commun 2011;32:113-120.

18 Yamagishi H, Shirai N, Yoshiyama M, Teragaki M, Akioka K, Takeuchi K, Yoshikawa J, Ochi H: Incremental value of left ventricular ejection fraction for detection of multivessel coronary artery disease in exercise (201)Tl gated myocardial perfusion imaging. J Nucl Med 2002;43:131-139.

19 Berman DS, Kiat H, Friedman JD, Wang FP, van Train K, Matzer L, Maddahi J, Germano G: Separate acquisition rest thallium-201/stress technetium-99m sestamibi dual-isotope myocardial perfusion single-photon emission computed tomography: a clinical validation study. J Am Coll Cardiol 1993;22:1455-1464.
20 Zellweger MJ, Hachamovitch R, Kang X, Hayes SW, Friedman JD, Germano G, Berman DS: Threshold, incidence, and predictors of prognostically high-risk silent ischemia in asymptomatic patients without prior diagnosis of coronary artery disease. J Nucl Cardiol 2009;16:193-200.

21 Hsia J, Larson JC, Ockene JK, Sarto GE, Allison MA, Hendrix SL, Robinson JG, LaCroix AZ, Manson JE: Resting heart rate as a low tech predictor of coronary events in women: prospective cohort study. BMJ 2009;338:b219.

22 Williams PT: Physical fitness and activity as separate heart disease risk factors: a meta-analysis. Med Sci Sports Exerc 2001;33:754-761.

23 Peix A, Gonzalez A, Garcia EJ, Valiente J, Cabrera LO, Sixto S, Filgueiras CE, Cabale B, Hechavarria S, Gonzalez I, Carrillo R, Garcia-Barreto D: Left ventricular dysfunction secondary to ischemia in women with angina and normal coronary angiograms. J Womens Health (Larchmt) 2009;18:155161.

24 Lee IM, Rexrode KM, Cook NR, Manson JE, Buring JE: Physical activity and coronary heart disease in women: is 'no pain, no gain' passe? JAMA 2001; 285:1447-1454.

25 Gregg EW, Cauley JA, Stone K, Thompson TJ, Bauer DC, Cummings SR, Ensrud KE: Relationship of changes in physical activity and mortality among older women. JAMA 2003;289:2379-2386.

26 Mora S, Lee IM, Buring JE, Ridker PM: Association of physical activity and body mass index with novel and traditional cardiovascular biomarkers in women. JAMA 2006;295:1412-1419.

27 Galal W, van Domburg RT, Feringa HH, Schouten O, Elhendy A, Bax JJ, Awara AM, Klein J, Poldermans D: Relation of body mass index to outcome in patients with known or suspected coronary artery disease. Am J Cardiol 2007;99:1485-1490.

28 Kang X, Shaw LJ, Hayes SW, Hachamovitch R, Abidov A, Cohen I, Friedman JD, Thomson LE, Polk D, Germano G, Berman DS: Impact of body mass index on cardiac mortality in patients with known or suspected coronary artery disease undergoing myocardial perfusion single-photon emission computed tomography. J Am Coll Cardiol 2006;47: 1418-1426.

29 Zavorsky GS: Cardiopulmonary aspects of obesity in women. Obstet Gynecol Clin North Am 2009;36: 267-284, viii.

$30 \mathrm{Wu}$ YW, Yen RF, Lee CM, Ho YL, Chou NK, Wang SS, Huang PJ: Diagnostic and prognostic value of dobutamine thallium-201 single-photon emission computed tomography after heart transplantation. J Heart Lung Transplant 2005;24:544550.

31 Morel O, Pezard P, Furber A, Le Jeune JJ, Vielle B, Denizot B, Jallet P: Thallium-201 right lung/ heart ratio during exercise in patients with coronary artery disease: relation to thallium-201 myocardial single-photon emission tomography, rest and exercise left ventricular function and coronary angiography. Eur J Nucl Med 1999;26:640-646.
2 Tadamura E, Kudoh T, Motooka M, Inubushi M, Shirakawa S, Hattori N, Okada T, Matsuda T, Koshiji T, Nishimura K, Matsuda K, Konishi J: Assessment of regional and global left ventricular function by reinjection T1-201 and rest Tc-99m sestamibi ECG-gated SPECT: comparison with three-dimensional magnetic resonance imaging. $\mathrm{J}$ Am Coll Cardiol 1999;33:991-997.

33 Omur O, Ozcan Z, Argon M, Acar ET: A comparative evaluation of Tl-201 and Tc-99m sestamibi myocardial perfusion spect imaging in diabetic patients. Int J Cardiovasc Imaging 2008;24:173-181.

34 Taillefer R, DePuey EG, Udelson JE, Beller GA, Latour Y, Reeves F: Comparative diagnostic accuracy of Tl-201 and Tc-99m sestamibi SPECT imaging (perfusion and ECG-gated SPECT) in detecting coronary artery disease in women. J Am Coll Cardiol 1997;29:69-77.

35 De Bondt P, Van de Wiele C, De Sutter J, De Winter F, De Backer G, Dierckx RA: Age- and genderspecific differences in left ventricular cardiac function and volumes determined by gated SPET. Eur J Nucl Med 2001;28:620-624

36 Yamagishi H, Yoshiyama M, Shirai N, Akioka K, Takeuchi K, Yoshikawa J: Impact of diabetes mellitus on worsening of the left ventricular ejection fraction in exercise-gated $201 \mathrm{Tl}$ myocardial single photon emission computed tomography in patients with coronary artery disease. Circ J 2003;67:839845.

37 Malkerneker D, Brenner R, Martin WH, Sampson UK, Feurer ID, Kronenberg MW, Delbeke D: CTbased attenuation correction versus prone imaging to decrease equivocal interpretations of rest/stress Tc-99m tetrofosmin SPECT MPI. J Nucl Cardiol 2007;14:314-323.

38 Pazhenkottil AP, Ghadri JR, Nkoulou RN, Wolfrum M, Buechel RR, Kuest SM, Husmann L, Herzog BA, Gaemperli O, Kaufmann PA: Improved outcome prediction by SPECT myocardial perfusion imaging after CT attenuation correction. J Nucl Med 2011;52:196-200.

39 Thompson RC, Heller GV, Johnson LL, Case JA, Cullom SJ, Garcia EV, Jones PG, Moutray KL, Bateman TM: Value of attenuation correction on ECG-gated SPECT myocardial perfusion imaging related to body mass index. J Nucl Cardiol 2005;12: 195-202.

40 Hendel RC, Berman DS, Di Carli MF, Heidenreich PA, Henkin RE, Pellikka PA, Pohost GM, Williams KA: ACCF/ASNC/ACR/AHA/ASE/SCCT/ SCMR/SNM 2009 appropriate use criteria for cardiac radionuclide imaging: a report of the American College of Cardiology Foundation Appropriate Use Criteria Task Force, the American Society of Nuclear Cardiology, the American College of Radiology, the American Heart Association, the American Society of Echocardiography, the Society of Cardiovascular Computed Tomography, the Society for Cardiovascular Magnetic Resonance, and the Society of Nuclear Medicine. Circulation 2009;119:e561-587. 